\title{
"Minimalist" resection for thymoma: Is less really more?
}

\author{
James Huang, MD
}

From the Thoracic Service, Department of Surgery, Memorial Sloan Kettering Cancer Center, New York, NY Disclosures: Author has nothing to disclose with regard to commercial support.

Received for publication June 23, 2017; accepted for publication July 6, 2017; available ahead of print Aug 4, 2017.

Address for reprints: James Huang, MD, Memorial Sloan Kettering Cancer Center, 1275 York Ave, New York, NY 10065 (E-mail: huangj@mskcc.org).

J Thorac Cardiovasc Surg 2017;154:1466-7

$0022-5223 / \$ 36.00$

Copyright (c 2017 by The American Association for Thoracic Surgery

http://dx.doi.org/10.1016/j.jtcvs.2017.07.001

Patients with myasthenia gravis (MG) pose a particular challenge for perioperative management because of their risks for muscle weakness, respiratory insufficiency, and myasthenic crises. Although these patients typically have their conditions optimized medically before surgery with respect to their immunomodulatory regimens and steroids, the anesthetic management of these patients remains potentially problematic. Standard agents typically used in the course of general anesthesia, neuromuscular blocking agents in particular, can exacerbate their myasthenia and precipitate a myasthenic crisis. These patients may have difficulty being extubated and may require intensive care and urgent plasma exchange.

In this issue of the Journal, Pompeo and colleagues ${ }^{1}$ present a small case series describing a novel "minimalist" approach to thymectomy in three patients with small thymomas and associated MG. Pompeo and colleagues ${ }^{1}$ used a uniportal thoracoscopic approach without general anesthesia. The procedure was conducted from the right side of the chest on an unintubated, spontaneously breathing patient, under the premise that avoidance of intubation, single-lung ventilation, and the use of any paralytic agents would be beneficial for the patient with MG.

Thoracic procedures, including lung resections, in awake patients have been previously reported by Pompeo and colleagues, ${ }^{1}$ as well as by multiple other authors. ${ }^{2,3}$ The application of this strategy to this particular group of patients would seem to have some intuitive appeal because it avoids the risks of general anesthesia. Pompeo and colleagues ${ }^{1}$ have termed their strategy an "ultra minimally invasive or minimalist" approach that combines regional anesthesia and maintenance of spontaneous ventilation with uniportal thoracoscopy. Although this is a case report of only 3 cases, the successful conduct of this approach without any apparent complications speaks to its feasibility and potential as an avenue to continue exploring.

Some counterpoints, however, are in order. Although the three patients were reportedly in either Myasthenia Gravis Foundation of America class 2 or 3, none of them required any steroids, suggesting that their MG manifestations were

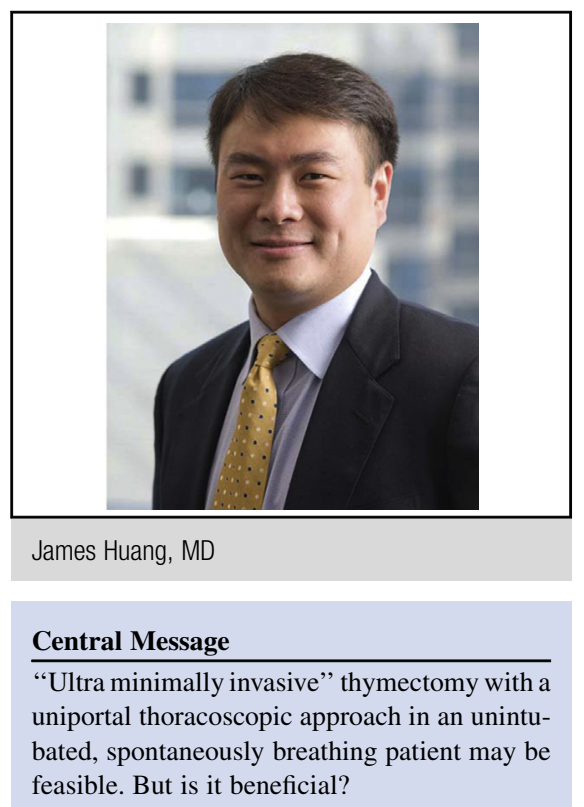

See Article page 1463

fairly moderate. Perhaps some of the best prospective data we have about the risks of thymectomy in patients with MG comes from the recent MGTX multicenter randomized trial. ${ }^{4}$ Interestingly, the patients in that trial all underwent open sternotomy, rather than minimally invasive surgery, yet the complication rate was only $2 \%$ and there was $0 \%$ mortality. The patients in that trial were maintained on fairly high doses of prednisone, however, attesting the importance of preoperative medical optimization.

From an oncologic perspective, one has to consider whether the "ultra minimally invasive" approach risks potentially compromising the quality of the resection. Adequate visualization can be difficult in the tight confines of the anterior mediastinum, and carbon dioxide insufflation can greatly improve exposure. The ability to use insufflation may be limited, however, in the spontaneously breathing patient. Although all 3 patients had complete resections, these were all small tumors, and R0 resections should be a given. The radicality of an "extended" thymectomy is always somewhat subjective; without entering the contralateral pleura, however, it does raise questions about the degree of mediastinal exenteration from a unilateral, uniportal approach. Nevertheless, the successful completion of these cases is noteworthy. We await additional short-term and long-term outcomes as more experience is gained with this approach. 


\section{References}

1. Pompeo E, Dauri M, Massa R, Peer M. Minimalist thoracoscopic resection of thymoma associated with myasthenia gravis. J Thorac Cardiovasc Surg. 2017;154: 1463-5.

2. Pompeo E, Mineo T. Awake operative videothoracoscopic pulmonary resections. Thorac Surg Clin. 2008;18:311-20.

3. Pompeo E, Tacconi F, Mineo T. Awake video-assisted thoracoscopic biopsy in complex anterior mediastinal masses. Thorac Surg Clin. 2010; 20:225-33.

4. Wolfe GI, Kaminski HJ, Sonnett JR, Aban IB, Kuo HC, Cutter GR. Randomized trial of thymectomy in myasthenia gravis. N Engl J Med. 2016; 375:511-22. 